\title{
NOTES
}

\section{Preparation and Viscoelastic Behavior of (Meth)acrylate Ionomers Crosslinked by Titanium(IV), Zirconium(IV) and Niobium(V) Ions}

\author{
Yasuo GoTOH, ${ }^{\dagger}$ Yutaka OHKOSHI, and Masanobu NAGURA \\ Faculty of Textile Science and Technology, Shinshu University, 3-15-1 Tokida, Ueda 386-8567, Japan
}

(Received August 7, 2003; Accepted December 4, 2003)

KEY WORDS Ionomer / Titanium / Zirconium / Niobium /

Ionomers are crosslinked polymeric materials consisting of a hydrophobic backbone and a small amount of acid groups neutralized by metal cations. Ionomers have been done on a large number of studies, ${ }^{1-4}$ having the interesting feature that the structures and properties can be varied by changing the types of counter ions, a constituent of the matrix copolymer, and the degree of neutralization. Crosslinking by metal ions is an effective method for controlling the mechanical properties and enhancing the heat-resistance of the host polymers. However, most investigations on the use of metal ions for crosslinking have dealt with ionomers containing alkali metals or divalent ions such as alkaline earth and transition metals, leaving ionomers containing tetravalent metal ions remain largely uninvestigated. The few examples include halato-telechelic polyisoprenes crosslinked by titanium(IV) $\left(\mathrm{Ti}^{4+}\right)$ and zirconium(IV) $\left(\mathrm{Zr}^{4+}\right),{ }^{5-7}$ poly(methyl methacrylate-co-methacrylic acid) crosslinked by $\mathrm{Ti}^{4+}$ and $\mathrm{Zr}^{4+},{ }^{8}$ and acrylate ionomers dispersions crosslinked by $\mathrm{Zr}^{4+}{ }^{9}$ In particular, to the best of the authors' knowledge, there has been no study of pentavalent ionomers. In view of this, the authors have begun investigating in detail ionomers with metal ions of high valence.

In order to study the physical properties of ionomers containing tetravalent and pentavalent metal ions, poly(ethyl acrylate-co-acrylic acid) crosslinked by $\mathrm{Ti}^{4+}$ and $\mathrm{Zr}^{4+}$, and poly(methyl methacrylate-comethacrylic acid) crosslinked by Niobium(V) $\left(\mathrm{Nb}^{5+}\right)$ were prepared in this study, and their structures and viscoelastic behavior were investigated. The effect of the kind of metal ion on the mechanical properties and heat-resistance of the host polymer is also discussed.

\section{EXPERIMENTAL}

\section{Reagents}

Ethyl acrylate (EA), acrylic acid (AA), methyl methacrylate (MMA), and methacrylic acid (MAA) were purified by conventional methods. Titanium(IV) tetraisopropoxide $\left(\mathrm{Ti}(\mathrm{O}-\mathrm{i} \mathrm{Pr})_{4}\right), 85$-wt\% zirconium(IV) tetrabutoxide $\left(\mathrm{Zr}(\mathrm{O}-\mathrm{Bu})_{4}\right)$ butanol solution, and niobium $(\mathrm{V})$ pentaethoxide $\left(\mathrm{Nb}(\mathrm{O}-\mathrm{Et})_{5}\right)$ were used as metal sources without purification. Benzoyl peroxide (BPO) as an initiator was recrystallized from benzene solution. All reagents were purchased from Wako Pure Chemical Industries, Ltd.

\section{Preparation of Ionomers}

Preparation of acrylate ionomers crosslinked by $\mathrm{Ti}^{4+}$ and $\mathrm{Zr}^{4+}$ was carried out as follows. After mixing EA and AA at the prescribed molar ratio, tetraalkoxide of titanium(IV) or zirconium(IV) equivalent to $\mathrm{AA}$ (i.e., molar ratio $[\mathrm{AA}] /[$ metal ion $]=4$ ) was added to the mixture. The mixtures containing the metalalkoxides were allowed to stand at ambient temperature for $1 \mathrm{~h}$, and then BPO was dissolved in each solution. Each mixture was then poured into a mold made of two Teflon plates with a silicone spacer of $1 \mathrm{~mm}$ thickness, and bulk-polymerized at $70^{\circ} \mathrm{C}$ for $2 \mathrm{~h}$ and then at $95^{\circ} \mathrm{C}$ for $24 \mathrm{~h}$ under dry $\mathrm{N}_{2}$. After polymerization, all ionomers were dried at $120^{\circ} \mathrm{C}$ for $24 \mathrm{~h}$ under vacuum to remove residues in the specimens. Acrylate ionomers crosslinked by $\mathrm{Ti}^{4+}$ and $\mathrm{Zr}^{4+}$ are labeled P(EA/AA)-Ti and P(EA/AA)$\mathrm{Zr}$, respectively. The $\mathrm{Nb}^{5+}$-crosslinked ionomer of P(MMA-co-MAA) was prepared by the same preparation procedure, except for the addition of niobium $(\mathrm{V})$ pentaethoxide equivalent to MAA (i.e., molar ratio $[\mathrm{MAA}] /\left[\mathrm{Nb}^{5+}\right]=5$ ) to the monomer mixture. Methacrylate ionomers crosslinked by $\mathrm{Nb}^{5+}$ and $\mathrm{Ti}^{4+}$ are labeled P(MMA/MAA)-Nb and P(MMA/MAA)-Ti, respectively. Data for $\mathrm{P}(\mathrm{MMA} / \mathrm{MAA})-\mathrm{Ti}$ is cited from a previous paper. ${ }^{8}$ Table I summarizes the labels and compositions of the ionomers. For example, "Ti", "E" and "91" in a code "Ti-E-91" mean "Ti-crosslinking", "ethyl acrylate ionomer", and the composition of "EA/AA $=9 / 1$ " in molar ratio. For compar-

${ }^{\dagger}$ To whom correspondence should be addressed (Tel: 0268-21-5366, Fax: 0268-21-5454, E-mail: ygotohy@ giptc.shinshu-u.ac.jp). 
Table I. Composition of the (meth)acrylate ionomers crosslinked by $\mathrm{Ti}^{4+}, \mathrm{Zr}^{4+}$, and $\mathrm{Nb}^{5+}$

\begin{tabular}{|c|c|c|c|c|c|}
\hline Ionomer & Code & Monomer (1) & Monomer (2) & Metalalkoxide & $\mathrm{BPO}$ \\
\hline \multirow{4}{*}{$\mathrm{P}(\mathrm{EA} / \mathrm{AA})-\mathrm{Ti}$} & Ti-E-91 & EEA: $9.0 \mathrm{~g}(90 \mathrm{mmol})$ & AA: $0.72 \mathrm{~g}(10 \mathrm{mmol})$ & $\mathrm{Ti}(\mathrm{O}-i \mathrm{Pr})_{4}: 0.7106 \mathrm{~g}(2.5 \mathrm{mmol})$ & $0.0972 \mathrm{~g}$ \\
\hline & Ti-E-82 & EEA: $8.0 \mathrm{~g}(80 \mathrm{mmol})$ & AA: $1.44 \mathrm{~g}(20 \mathrm{mmol})$ & $\mathrm{Ti}(\mathrm{O}-i \mathrm{Pr})_{4}: 1.4212 \mathrm{~g}(5.0 \mathrm{mmol})$ & $0.0972 \mathrm{~g}$ \\
\hline & Ti-E-73 & EEA: $7.0 \mathrm{~g}(70 \mathrm{mmol})$ & AA: $2.16 \mathrm{~g}(30 \mathrm{mmol})$ & $\operatorname{Ti}(\mathrm{O}-i \mathrm{Pr})_{4}: 2.1317 \mathrm{~g}(7.5 \mathrm{mmol})$ & $0.0972 \mathrm{~g}$ \\
\hline & Ti-E-64 & EEA: $6.0 \mathrm{~g}(60 \mathrm{mmol})$ & AA: $2.88 \mathrm{~g}(40 \mathrm{mmol})$ & $\operatorname{Ti}(\mathrm{O}-i \mathrm{Pr})_{4}: 2.8423 \mathrm{~g}(10.0 \mathrm{mmol})$ & $0.0972 \mathrm{~g}$ \\
\hline \multirow{4}{*}{$\mathrm{P}(\mathrm{EA} / \mathrm{AA})-\mathrm{Zr}$} & Zr-E-91 & EEA: $9.0 \mathrm{~g}(90 \mathrm{mmol})$ & AA: $0.72 \mathrm{~g}(10 \mathrm{mmol})$ & $\mathrm{Zr}(\mathrm{O}-\mathrm{Bu})_{4}^{\mathrm{a}}: 1.129 \mathrm{~g}\left(2.5 \mathrm{mmol}^{\mathrm{b}}\right)$ & $0.0972 \mathrm{~g}$ \\
\hline & Zr-E-82 & EEA: $8.0 \mathrm{~g}(80 \mathrm{mmol})$ & AA: $1.44 \mathrm{~g}(20 \mathrm{mmol})$ & $\mathrm{Zr}(\mathrm{O}-\mathrm{Bu})_{4}{ }^{\mathrm{a}}: 2.257 \mathrm{~g}\left(5.0 \mathrm{mmol}^{\mathrm{b}}\right)$ & $0.0972 \mathrm{~g}$ \\
\hline & Zr-E-73 & EEA: $7.0 \mathrm{~g}(70 \mathrm{mmol})$ & AA: $2.16 \mathrm{~g}(30 \mathrm{mmol})$ & $\mathrm{Zr}(\mathrm{O}-\mathrm{Bu})_{4}{ }^{\mathrm{a}}: 3.385 \mathrm{~g}\left(7.5 \mathrm{mmol}^{\mathrm{b}}\right)$ & $0.0972 \mathrm{~g}$ \\
\hline & Zr-E-64 & EEA: $6.0 \mathrm{~g}(60 \mathrm{mmol})$ & AA: $2.88 \mathrm{~g}(40 \mathrm{mmol})$ & $\mathrm{Zr}(\mathrm{O}-\mathrm{Bu})_{4}{ }^{\mathrm{a}}: 4.514 \mathrm{~g}\left(10.0 \mathrm{mmol}^{\mathrm{b}}\right)$ & $0.0972 \mathrm{~g}$ \\
\hline \multirow{4}{*}{$\mathrm{P}(\mathrm{MMA} / \mathrm{MAA})-\mathrm{Nb}$} & $\mathrm{Nb}-\mathrm{M}-91$ & MMA: $9.0 \mathrm{~g}(90 \mathrm{mmol})$ & MAA: $0.861 \mathrm{~g}(10 \mathrm{mmol})$ & $\mathrm{Nb}(\mathrm{O}-\mathrm{Et})_{5}: 0.6364 \mathrm{~g}(2.0 \mathrm{mmol})$ & $0.0986 \mathrm{~g}$ \\
\hline & $\mathrm{Nb}-\mathrm{M}-82$ & MMA: $8.0 \mathrm{~g}(80 \mathrm{mmol})$ & MAA: $1.722 \mathrm{~g}(20 \mathrm{mmol})$ & $\mathrm{Nb}(\mathrm{O}-\mathrm{Et})_{5}: 1.2728 \mathrm{~g}(4.0 \mathrm{mmol})$ & $0.0986 \mathrm{~g}$ \\
\hline & $\mathrm{Nb}-\mathrm{M}-73$ & MMA: $7.0 \mathrm{~g}(70 \mathrm{mmol})$ & MAA: $2.583 \mathrm{~g}(30 \mathrm{mmol})$ & $\mathrm{Nb}(\mathrm{O}-\mathrm{Et})_{5}: 1.9093 \mathrm{~g}(6.0 \mathrm{mmol})$ & $0.0986 \mathrm{~g}$ \\
\hline & $\mathrm{Nb}-\mathrm{M}-64$ & MMA: $6.0 \mathrm{~g}(60 \mathrm{mmol})$ & MAA: $3.444 \mathrm{~g}(40 \mathrm{mmol})$ & $\mathrm{Nb}(\mathrm{O}-\mathrm{Et})_{5}: 2.5457 \mathrm{~g}(8.0 \mathrm{mmol})$ & $0.0986 \mathrm{~g}$ \\
\hline \multirow{4}{*}{$\mathrm{P}(\mathrm{MMA} / \mathrm{MAA})-\mathrm{Ti}^{\mathrm{c}}$} & Ti-M-91 & MMA: $9.0 \mathrm{~g}(90 \mathrm{mmol})$ & MAA: $0.861 \mathrm{~g}(10 \mathrm{mmol})$ & $\mathrm{Ti}(\mathrm{O}-i \mathrm{Pr})_{4}: 0.7106 \mathrm{~g}(2.5 \mathrm{mmol})$ & $0.0986 \mathrm{~g}$ \\
\hline & Ti-M-82 & MMA: $8.0 \mathrm{~g}(80 \mathrm{mmol})$ & MAA: $1.722 \mathrm{~g}(20 \mathrm{mmol})$ & $\mathrm{Ti}(\mathrm{O}-i \mathrm{Pr})_{4}: 1.4212 \mathrm{~g}(5.0 \mathrm{mmol})$ & $0.0986 \mathrm{~g}$ \\
\hline & Ti-M-73 & MMA: $7.0 \mathrm{~g}(70 \mathrm{mmol})$ & MAA: $2.583 \mathrm{~g}(30 \mathrm{mmol})$ & $\operatorname{Ti}(\mathrm{O}-i \mathrm{Pr})_{4}: 2.1317 \mathrm{~g}(7.5 \mathrm{mmol})$ & $0.0986 \mathrm{~g}$ \\
\hline & Ti-M-64 & MMA: $6.0 \mathrm{~g}(60 \mathrm{mmol})$ & MAA: $3.444 \mathrm{~g}(40 \mathrm{mmol})$ & $\operatorname{Ti}(\mathrm{O}-i \mathrm{Pr})_{4}: 2.8423 \mathrm{~g}(10.0 \mathrm{mmol})$ & $0.0986 \mathrm{~g}$ \\
\hline
\end{tabular}

a $85 \mathrm{wt} \% \mathrm{Zr}(\mathrm{O}-\mathrm{Bu})_{4}$ butanol solution ${ }^{\mathrm{b}}$ molar quantity of $\mathrm{Zr}(\mathrm{O}-\mathrm{Bu})_{4}$ content in $85 \mathrm{wt} \% \mathrm{Zr}(\mathrm{O}-\mathrm{Bu})_{4}$ butanol solution ${ }^{\mathrm{c}}$ This data is cited from Ref 8 .

ison, ion-free polyethylacrylate (PEA) and polymethylmethacrylate (PMMA) homopolymers were polymerized under the same polymerization conditions.

\section{Measurements}

Infrared (IR) absorption spectra were measured using a Perkin-Elmer 1640 Fourier transform IR (FT-IR) spectrometer. IR measurements of $\mathrm{P}(\mathrm{EA} / \mathrm{AA})-\mathrm{Ti}$ and $\mathrm{P}(\mathrm{EA} / \mathrm{AA})-\mathrm{Zr}$ were conducted in attenuated total reflectance (ATR) mode with KRS-5 as the internal reflection element. Ultraviolet-visible (UV-vis) absorption spectra were obtained on a U-3500 UV-vis-near infrared spectrophotometer by Hitachi, Ltd. The lightpath length for all specimens was $1 \mathrm{~mm}$. Dynamic mechanical thermal analysis (DMTA) was carried out to obtain the storage modulus $\left(E^{\prime}\right)$ and loss tangent $(\tan \delta)$ using an ITK DVA-200 instrument in tensile mode with a frequency of $10 \mathrm{~Hz}$ and a heating rate of $5^{\circ} \mathrm{C} / \mathrm{min}$. Strips of dimensions $20 \mathrm{~mm} \times 4 \mathrm{~mm} \times$ $1 \mathrm{~mm}$ were used for measurements.

\section{RESULTS AND DISCUSSION}

\section{Acrylate Ionomers Crosslinked by $\mathrm{Ti}^{4+}$ and $\mathrm{Zr}^{4+}$}

Metalalkoxides such as $\mathrm{Ti}(\mathrm{O}-\mathrm{iPr})_{4}$ and $\mathrm{Zr}(\mathrm{O}-\mathrm{Bu})_{4}$ are strong bases and thus rapidly react with carboxylic acids of AA through neutralization. In the case of a molar ratio of $[\mathrm{AA}] /\left[\mathrm{Ti}^{4+}\right]=1$, a metal acrylate and an alcohol are generated as follows. ${ }^{10-12}$

$$
\mathrm{M}(\mathrm{OR})_{4}+\mathrm{AA} \rightarrow \mathrm{M}(\mathrm{OR})_{3} \mathrm{AA}^{-}+\mathrm{HOR}
$$

where $\mathrm{M}, \mathrm{OR}$ and $\mathrm{AA}^{-}$represent the metal ion, the alkoxy group, and deprotonated $\mathrm{AA}\left(\mathrm{CH}_{2}=\mathrm{CHCOO}^{-}\right)$.
When alkoxides were added to the mixtures of EA and AA, the color immediately changed and an exothermic reaction occurred, indicating the generation of metal complexes with $\mathrm{AA}^{-}$. Figure $1 \mathrm{a}$ and $1 \mathrm{~b}$ shows the IR spectra for P(EA/AA)-Ti and P(EA/AA)-Zr, respectivley. Both ionomers exhibit a broad absorption peak around $1500-1600 \mathrm{~cm}^{-1}$, which is not seen in PEA. These absorption peaks are assigned to a $\mathrm{COO}^{-}$asymmetric stretching band $\left(v_{\mathrm{a}}\left(\mathrm{COO}^{-}\right)\right)$of carboxylates coordinating to the metal ion, ${ }^{10-14}$ indicating the formation of metal acrylate in the ionomers. There are three main coordination modes for carboxylate combination with metal ions; monodentate, bidentate chelating, and bidentate bridging:<smiles>[M]OC([R])[O-]</smiles>

(I)<smiles></smiles>

(II)<smiles>[M]OC([R])O[M]</smiles>

(III)
These coordination modes can be identified by $\Delta v=v_{\mathrm{a}}-v_{\mathrm{s}},{ }^{15}$ where $\Delta v$ is the frequency separation and $v_{\mathrm{s}}$ is the frequency of the $\mathrm{COO}^{-}$symmetric stretching band of the carboxylate. For P(EA/AA)$\mathrm{Ti}$, the frequencies of $v_{\mathrm{a}}\left(\mathrm{COO}^{-}\right)$and $v_{\mathrm{s}}\left(\mathrm{COO}^{-}\right)$are $1560 \mathrm{~cm}^{-1}$ and $1420 \mathrm{~cm}^{-1}$, respectively, and thus $\Delta v=140 \mathrm{~cm}^{-1}$. In general, $\Delta v$ of monodentate $\left(>200 \mathrm{~cm}^{-1}\right)$ is much larger than that of bidentate chelating or bidentate bridging, indicating that the coordination state of the carboxylate is bidentate chelating (II) or bidentate bridging (III), but not monodentate (I). ${ }^{14}$ The $\Delta v$ value for $\mathrm{P}(\mathrm{EA} / \mathrm{AA})-\mathrm{Zr}$ is $117 \mathrm{~cm}^{-1}$, which is close to the value for $\mathrm{P}(\mathrm{EA} /$ AA) $-\mathrm{Ti}$, and thus the coordination mode may be sim- 


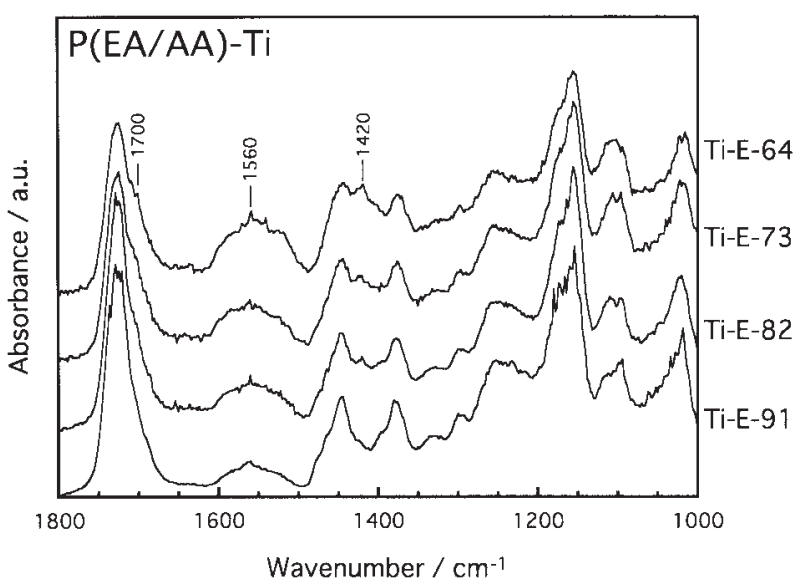

(a)

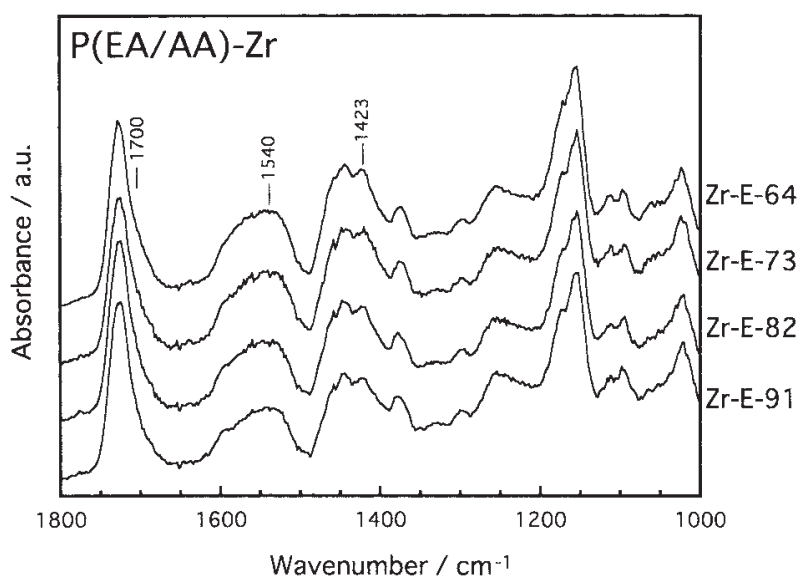

(b)

Figure 1. IR spectra of (a) $\mathrm{P}(\mathrm{EA} / \mathrm{AA})-\mathrm{Ti}$ and (b) $\mathrm{P}(\mathrm{EA} / \mathrm{AA})-$ Zr.

ilar to that of $\mathrm{P}(\mathrm{EA} / \mathrm{AA})-\mathrm{Ti}$. For all ionomers, $\Delta v$ is close to that of bidentate chelating or bidentate bridging. Furthermore, the absorption band of $v_{a}\left(\mathrm{COO}^{-}\right)$is quite broad and asymmetric, apparently consisting of a number of indistinct peaks, indicating that the (II) and (III) coordination modes may coexist.

A maximum of 4 AA molecules can be expected to react with $\mathrm{Ti}^{4+}$ or $\mathrm{Zr}^{4+}$, because these metal ions are tetravalent cations, AA is a monovalent acid, and the nominal molar ratio [AA]/[metalalkoxide] is 4 in the present specimens. As shown in Figure 1a, the carbonyl stretching $[v(\mathrm{C}=\mathrm{O})]$ band of unreacted AAs which are dimerized through hydrogen bonding occurs at $1700 \mathrm{~cm}^{-1}$ as a small shoulder. This means that neutralization does not perfectly proceed between AA and $\mathrm{Ti}(\mathrm{O}-\mathrm{iPr})_{4}$. $\mathrm{P}(\mathrm{EA} / \mathrm{AA})-\mathrm{Zr}$ also exhibits a weak absorption of $v(\mathrm{C}=\mathrm{O})$ of unreacted $\mathrm{AA}$ at 1700 $\mathrm{cm}^{-1}$ as a shoulder in Figure $1 \mathrm{~b}$. It is likely that the absorption intensities of $v\left(\mathrm{COO}^{-}\right)$for unreacted AA in $\mathrm{P}(\mathrm{EA} / \mathrm{AA})-\mathrm{Zr}$ are smaller than those of $\mathrm{P}(\mathrm{EA} /$ AA)-Ti. Therefore, the number of $\mathrm{AA}^{-}$ions coordinating to $\mathrm{Zr}^{4+}$ is larger than for $\mathrm{Ti}^{4+}$ because the ionic

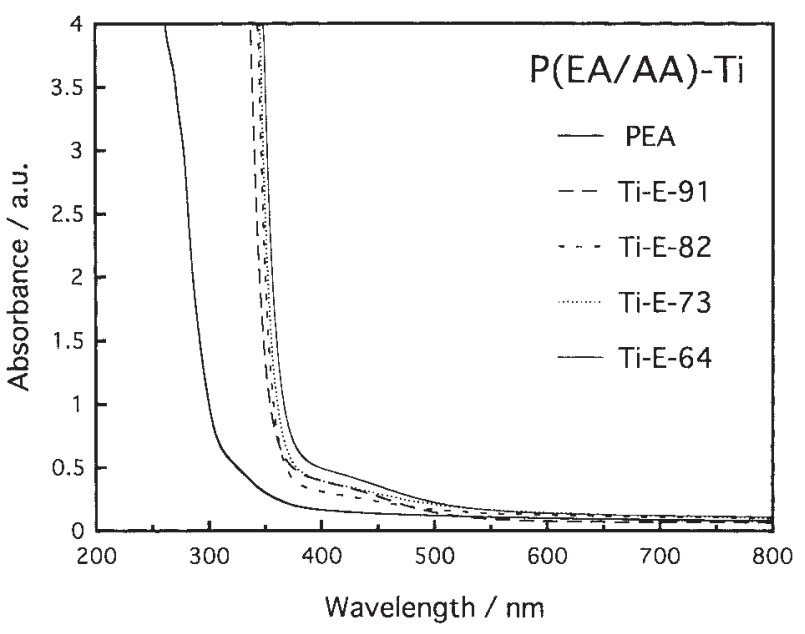

(a)

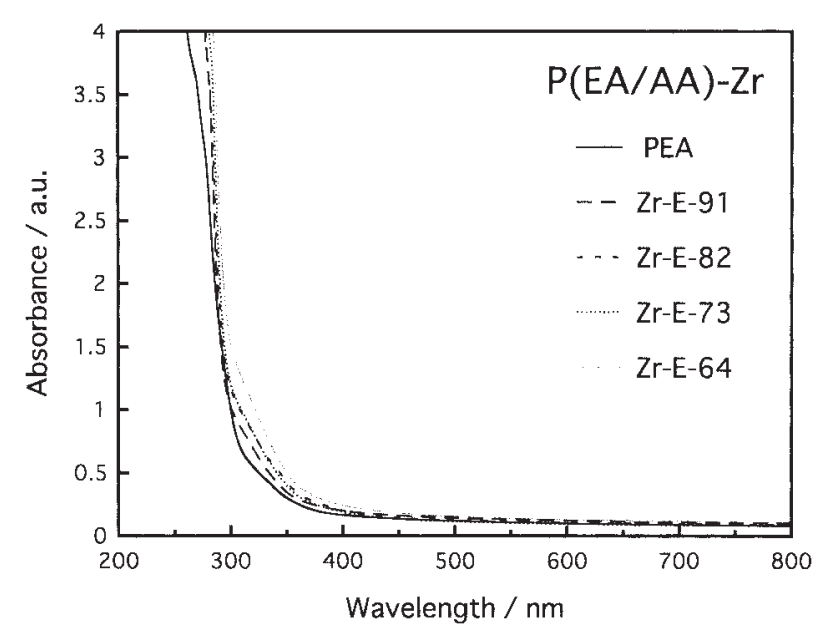

(b)

Figure 2. UV-vis spectra of (a) $\mathrm{P}(\mathrm{EA} / \mathrm{AA})-\mathrm{Ti}$ and (b) $\mathrm{P}(\mathrm{EA} /$ AA)-Zr.

radius and coordination number of $\mathrm{Zr}^{4+}$ are larger than those of $\mathrm{Ti}^{4+}$ (ionic radius $\mathrm{Ti}^{4+}: 0.61 \AA$, $\mathrm{Zr}^{4+}$ : $0.84 \AA$; coordination number (in the oxides) $\mathrm{Ti}^{4+}: 6$, $\left.\mathrm{Zr}^{4+}: 8\right){ }^{16}$

Figure $2 \mathrm{a}$ and $2 \mathrm{~b}$ shows the UV-vis spectra of $\mathrm{P}(\mathrm{EA} / \mathrm{AA})-\mathrm{Ti}$ and $\mathrm{P}(\mathrm{EA} / \mathrm{AA})-\mathrm{Zr}$, respectively. The spectrum of PEA is shown in each figure for comparison. Every ionomer showed high transparency, and $\mathrm{P}(\mathrm{EA} / \mathrm{AA})-\mathrm{Ti}$ and $\mathrm{P}(\mathrm{EA} / \mathrm{AA})-\mathrm{Zr}$ were yellowish and almost colorless, respectively. For P(EA/AA)Ti, extremely strong UV absorption was observed below ca. $360 \mathrm{~nm}$, which is useful as a UV cut-off filter. This absorption is considered to be caused by charge transfer between $\mathrm{Ti}^{4+}$ ion and oxygen of $-\mathrm{COO}^{-}$ groups from the results of the previous study. ${ }^{17}$ For $\mathrm{P}(\mathrm{EA} / \mathrm{AA})-\mathrm{Zr}$, an absorption edge is seen at around ca. $300 \mathrm{~nm}$, which is slightly but surely positioned at the longer wavelength side compared to that of neat PEA. This absorption of P(EA/AA)-Ti may be charge transfer, and it is possible that the difference between the wavelengths of absorption edges of $\mathrm{P}(\mathrm{EA} / \mathrm{AA})-\mathrm{Ti}$ 
and $\mathrm{P}(\mathrm{EA} / \mathrm{AA})-\mathrm{Zr}$ is attributed to the difference in the optical electronegativity of the metal ions.

Figure $3 \mathrm{a}$ and $3 \mathrm{~b}$ shows the temperature dependence of $E^{\prime}$ and $\tan \delta$ for P(EA/AA)-Ti and P(EA/

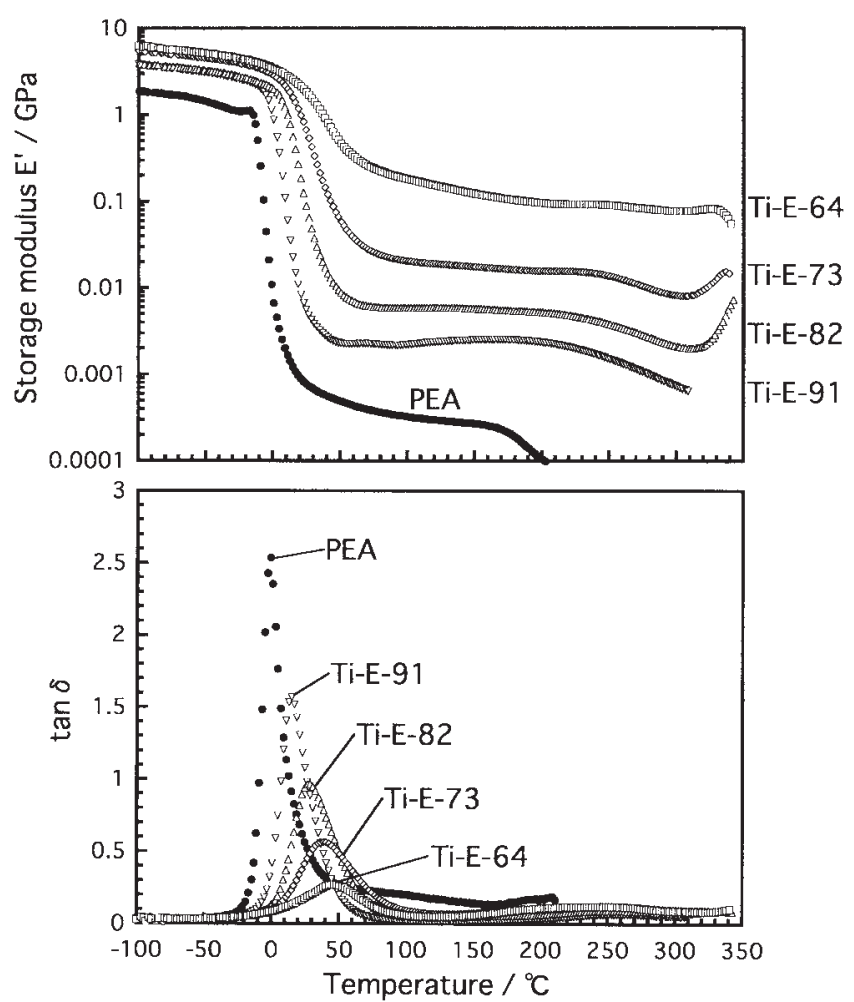

(a)

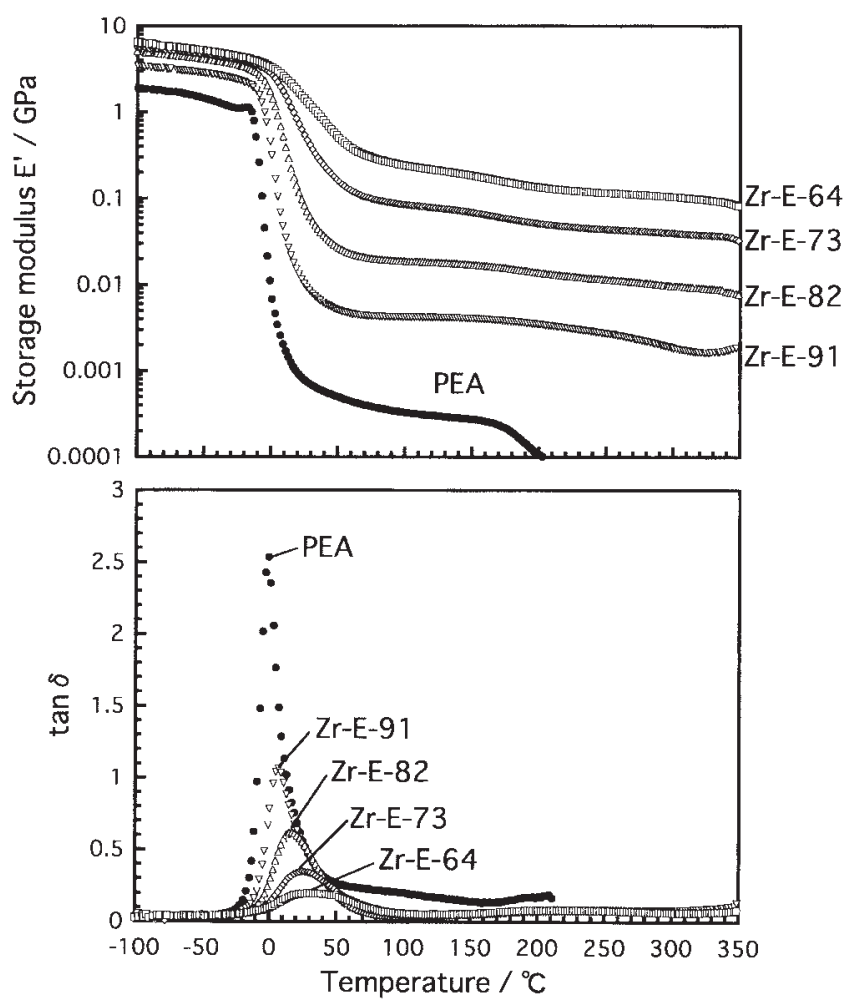

(b)

Figure 3. Temperature dependence of storage modulus $E^{\prime}$ and $\tan \delta$ of (a) $\mathrm{P}(\mathrm{EA} / \mathrm{AA})-\mathrm{Ti}$ and (b) $\mathrm{P}(\mathrm{EA} / \mathrm{AA})-\mathrm{Zr}$.
AA) $-\mathrm{Zr}$, respectively. The result for PEA is shown in each figure for comparison. For PEA, $E^{\prime}$ abruptly decreases at -10 and $180^{\circ} \mathrm{C}$, and the specimen was fractured at around $200^{\circ} \mathrm{C}$. The low-temperature decrease of $E^{\prime}$ is associated with the glass transition temperature $\left(T_{\mathrm{g}}\right)$, whereas the high-temperature one is due to melt-flow. On the other hand, all the ionomers undergo a glass-rubber transition in the temperature range from -10 to $50{ }^{\circ} \mathrm{C}$ and above this temperature show a rubbery plateau which extends beyond $300{ }^{\circ} \mathrm{C}$ without melt-flow, indicating high heat resistance of the ionomers. In addition, the peak temperatures of $\tan \delta$ around room temperature due to glass transition increase with the metal ion content. These results indicate that the increased metal ion content would lead to the formation of the more densely crosslinked network. However, the $T_{\mathrm{g}} \mathrm{s}$ of the ionomers in this study are much lower than those of poly(EA/ AA) ionomers neutralized with $\mathrm{Ca}^{2+}, \mathrm{Ba}^{2+}, \mathrm{Li}^{+}$, and $\mathrm{Na}^{+18}$ when compared at the almost same AA content. Therefore, it can be said that the density of crosslinks in the present ionomers is lower. This means that a part of the tetravalent metal ions introduced into the ionomers do not participate the neutralization reaction of AA, which is supported by IR results shown in Figure 1.

Some poly(EA/AA) ionomers neutralized with alkaline or alkaline-earth metal ions have the cluster $T_{\mathrm{g}}$ which is the second glass transition temperature attributed to the ion-rich phase, i.e. ionic cluster. The cluster $T_{\mathrm{g}}$ can be observed above the matrix $T_{\mathrm{g}}$ as a peak in a $\tan \delta$ curve and $E^{\prime}$ drops at the corresponding temperature. ${ }^{19,20}$ No such second $T_{\mathrm{g}}$ peak was detected in this study. Thus, this may imply that the phase-separated structures due to ionic association in $\mathrm{P}(\mathrm{EA} /$ $\mathrm{AA})-\mathrm{Ti}$ and $\mathrm{P}(\mathrm{EA} / \mathrm{AA})-\mathrm{Zr}$ are different from those of ionomers neutralized with alkaline and alkalineearth metal ions, which needs further study.

The storage modulus of the ionomers varied in the glassy and rubbery states depending on the metal ion content. That is, interchain crosslinking by $\mathrm{Ti}^{4+}$ or $\mathrm{Zr}^{4+}$ effectively controls the modulus of the ionomers. The difference in $E^{\prime}$ above $T_{\mathrm{g}}$ is much greater that that below $T_{\mathrm{g}}$.

The modulus of $\mathrm{P}(\mathrm{EA} / \mathrm{AA})-\mathrm{Zr}$ was higher than that of $\mathrm{P}(\mathrm{EA} / \mathrm{AA})-\mathrm{Ti}$ above $50^{\circ} \mathrm{C}$ for the same AA content. The heat resistance of $\mathrm{P}(\mathrm{EA} / \mathrm{AA})-\mathrm{Zr}$ was also higher than that of $\mathrm{P}(\mathrm{EA} / \mathrm{AA})-\mathrm{Ti}$, because $\mathrm{P}(\mathrm{EA} /$ AA) $-\mathrm{Zr}$ allowed the DMTA measurement up to $350^{\circ} \mathrm{C}$, whereas $\mathrm{P}(\mathrm{EA} / \mathrm{AA})-\mathrm{Ti}$ fractured at around $340^{\circ} \mathrm{C}$. This may originate from the larger number of $\mathrm{AA}^{-}$coordinating to $\mathrm{Zr}^{4+}$, as pointed out by the IR results. 


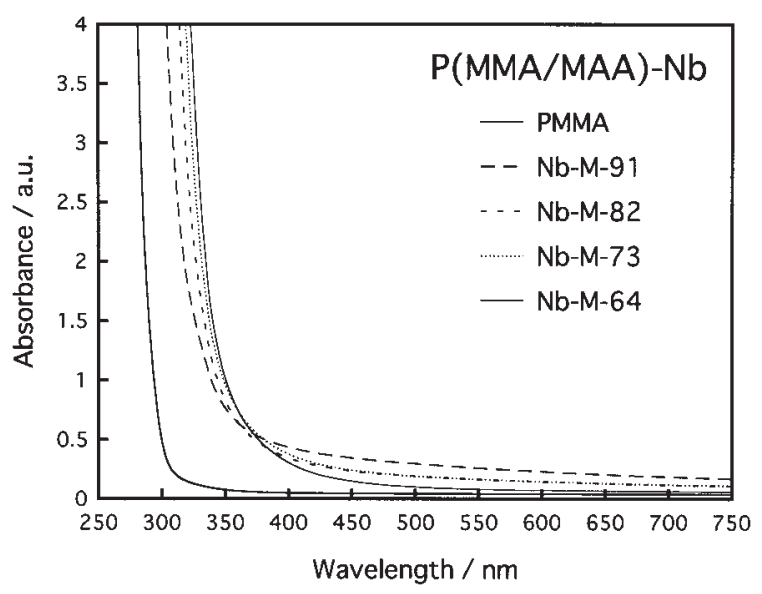

Figure 4. UV-vis spectra of $\mathrm{P}(\mathrm{MMA} / \mathrm{MAA})-\mathrm{Nb}$.

\section{Methacrylate Ionomers Crosslinked by $\mathrm{Nb}^{5+}$}

Figure 4 shows UV-vis spectra of P(MMA/MAA)$\mathrm{Nb}$. The spectrum of PMMA is shown in each figure for comparison. P(MMA/MAA)-Nb is yellowish and highly transparent, and exhibits strong UV absorption below $350 \mathrm{~nm}$ similar to P(EA/AA)-Ti. This absorption may be caused by charge transfer between $\mathrm{Nb}^{5+}$ and oxygen of $-\mathrm{COO}^{-}$groups in MAA, analogous to $\mathrm{Nb}_{2} \mathrm{O}_{5} \cdot{ }^{21}$

Figure 5 shows the temperature dependence of $E^{\prime}$ and $\tan \delta$ for some ionomers of $\mathrm{P}(\mathrm{MMA} / \mathrm{MAA})-\mathrm{Nb}$ and $\mathrm{P}(\mathrm{MMA} / \mathrm{MAA})-\mathrm{Ti}$. For both ionomers, no sign of melt-flow was observed for the DMTA measure-

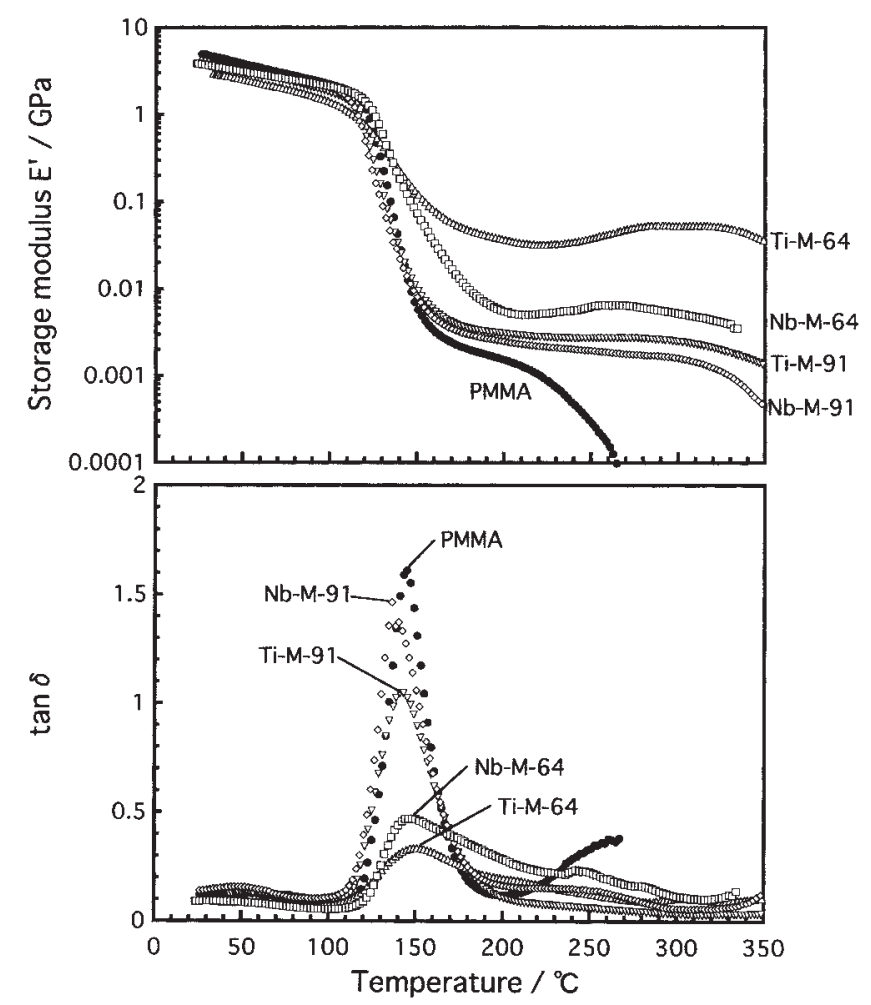

Figure 5. Temperature dependence of storage modulus $E^{\prime}$ and $\tan \delta$ of $\mathrm{P}(\mathrm{MMA} / \mathrm{MAA})-\mathrm{Nb}$ and $\mathrm{P}(\mathrm{MMA} / \mathrm{MAA})-\mathrm{Ti}$. ments up to $350^{\circ} \mathrm{C}$. When compared at the same MAA content, $E^{\prime}$ of P(MMA/MAA)-Nb was lower than that of $\mathrm{P}(\mathrm{MMA} / \mathrm{MAA})-\mathrm{Ti}$, particularly at high $\mathrm{Nb}^{5+}$ content, implying lower crosslinking density of the $\mathrm{Nb}^{5+}$-crosslinked ionomers. Additionally, the IR peak intensity of $v_{\mathrm{a}}\left(\mathrm{COO}^{-}\right)$of $\mathrm{MAA}^{-}$coordinating to $\mathrm{Nb}^{5+}$ was much lower than that of P(MMA/ MAA)-Ti (not shown here), although the coordination of $-\mathrm{COO}^{-}$to $\mathrm{Nb}^{5+}$ was confirmed. These results indicate less number of MAA-coordinates to $\mathrm{Nb}^{5+}$, and $\mathrm{Nb}^{5+}$ does not act as an effective crosslinker of molecular chains compared to the case for $\mathrm{Ti}^{4+}$. As the ionic radii of these ions are comparable $\left(\mathrm{Nb}^{5+}\right.$, ionic radius: $0.64 \AA$, coordination number (in the oxides): 6), ${ }^{16}$ another mechanism must be responsible. The coordination structures of these ionomers are currently being studied in further detail.

Acknowledgment. This work was supported by Grant-in-Aid for 21st Century COE Program by the Ministry of Education, Culture, Sports, Science, and Technology.

\section{REFERENCES}

1. L. Holliday, "Ionic Polymers," Halsted-Wiley, New York, N.Y., 1975.

2. A. Eisenberg and M. King, "Ion-Containing Polymers," Academic Press, New York, N.Y., 1977.

3. W. J. MacKnight and T. R. Earnest, J. Polym. Sci., Macromol. Rev., 16, 41 (1981).

4. S. Yano, N. Nagano, M. Hattori, E. Hirasawa, and K. Tadano, Macromolecules, 25, 368 (1992).

5. M. R. Tant, J. H. Song, G. L. Wilkes, J. Horrion, and R. Jerome, Polymer, 27, 1815 (1986).

6. P. Charlier, A. Corrias, R. Jerome, J. R. Regnard, G. Vlaic, and C. E. Williams, Conf. Proc.-Ital. Phys. Soc., 25, 937 (1990).

7. M. R. Tant, L. N. Venkateshwaran, J. H. Song, R. G. L. Subramanian Wilkes, P. Charlier, and R. Jerome, Polymer, 33, 1347 (1992).

8. Y. Gotoh, J. Imakita, Y. Ohkoshi, and M. Nagura, Polym. J., 32, 838 (2000).

9. N. P. S. Ricardo, N. P. S. Ricardo, R. Holmes, and C. Price, Polym. Eng. Sci., 39, 543 (1999).

10. M. Camail, M. Humbert, A. Margaillan, A. Riondel, and J. L. Vernet, Polymer, 39, 6525 (1998).

11. M. Camail, M. Humbert, A. Margaillan, and J. L. Vernet, Polymer, 39, 6533 (1998).

12. H. Sayilkan, S. Sener, E. Sener, and E. Arpac, J. Mater. Sci., 34, 5325 (1999).

13. K. H. Von Thiele, and M. Panse, Z. Anorg. Allg. Chem., 441, 23 (1978).

14. S. Doeuff, M. Henry, C. Sanchez, and J. Livage, J. NonCryst. Solids, 89, 206 (1987).

15. K. Nakamoto, "Infrared and Raman Spectra of Inorganic and Coordination Compounds," 5th ed, John Wiley \& Sons, 
New York, N.Y., 1997.

16. D. R. Lide ed., "Handbook of Chemistry and Physics," 76th ed., CRC Press, Boca Raton, FL, 1995.

17. Y. Gotoh, J. Imakita, Y. Ohkoshi, and M. Nagura, Kobunshi Ronbunshu, 57, 577 (2000).

18. H. Matsuura and A. Eisenberg, J. Polym. Sci., Polym. Phys.
Ed., 14, 1201 (1976).

19. J.-S. Kim, Y. H. Nah, and S.-S. Jarng, Polymer, 42, 42 (2001).

20. S.-H. Kim and J.-S. Kim, Macromolecules, 36, 2382 (2003).

21. M. Anpo, N. Aikawa, Y. Kubokawa, M. Che, C. Louis, and E. Giamello, J. Phys. Chem., 89, 5017 (1985). 